\title{
(2) OPEN ACCESS \\ Preterm infant circulating sex steroid levels are not altered by transfusion with adult male plasma: a retrospective multicentre cohort study
}

\author{
Anders K Nilsson (D) ,' Gunnel Hellgren, ${ }^{1,2}$ Ulrika Sjöbom, ${ }^{1,3}$ Andreas Landin, ${ }^{4}$ \\ Henrik Ryberg, ${ }^{4,5}$ Dirk Wackernagel (D) , ${ }^{6,7}$ David Ley, ${ }^{8}$ Ingrid Hansen Pupp, ${ }^{8}$ \\ Matti Poutanen, ${ }^{9,10}$ Claes Ohlsson, $^{10,11}$ Ann Hellstrom ${ }^{1}$
}

\begin{abstract}
Additional supplemental material is published online only. To view, please visit the journal online (http://dx.doi. org/10.1136/archdischild2021-323433)
\end{abstract}

For numbered affiliations see end of article.

Correspondence to Dr Anders K Nilsson, Institute of Neuroscience and Physiology, Department of Clinical Neuroscience, University of Gothenburg Sahlgrenska Academy, Goteborg, Sweden; anders.k.nilsson@gu.se

AKN and GH contributed equally.

Received 27 October 2021 Accepted 12 February 2022
Check for updates

(C) Author(s) (or their employer(s)) 2022. Re-use permitted under CC BY. Published by BMJ.

To cite: Nilsson AK, Hellgren G, Sjöbom U, et al. Arch Dis Child Fetal Neonatal Ed Epub ahead of print: [please include Day Month Year]. doi:10.1136/archdischild2021-323433

\section{ABSTRACT}

Objective To determine if plasma transfusions with male donor plasma to very preterm infants affect circulatory levels of sex steroids.

Design and patients Retrospective multicentre cohort study in 19 infants born at gestational age $<29$ weeks requiring plasma transfusion during their first week of life.

Setting Three neonatal intensive care units in Sweden. Main outcome measures Concentrations of sex steroids and sex hormone-binding globulin (SHBG) in donor plasma and infant plasma measured before and after a plasma transfusion and at 6, 12, 24 and 72 hours. Results The concentrations of progesterone, dehydroepiandrosterone and androstenedione were significantly lower in donor plasma than in infant plasma before the transfusion (median (Q1-Q3) 37.0 (37.0-37.0), 1918 (1325-2408) and 424 (303-534) vs 901 (599-1774), 4119 (2801-14 645) and 842 (443-1684) pg/mL), while oestrone and oestradiol were higher in donor plasma (17.4 (10.4-20.1) and 16.0 $(11.7-17.2)$ vs $3.1(1.1-10.2)$ and $0.25(0.25-0.25) \mathrm{pg} /$ $\mathrm{mL}$ ). Median testosterone and dihydrotestosterone (DHT) levels were 116-fold and 21-fold higher in donor plasma than pre-transfusion levels in female infants, whereas the corresponding difference was not present in male infants. Plasma sex steroid levels were unchanged after completed transfusion compared with pre-transfusion levels, irrespective of the gender of the receiving infant. The SHBG concentration was significantly higher in donor than in recipient plasma $(22.8(17.1-33.5)$ vs 10.2

$(9.1-12.3) \mathrm{nmol} / \mathrm{L})$ before transfusion but did not change in the infants after the transfusion.

Conclusions A single transfusion of adult male plasma to preterm infants had no impact on circulating sex steroid levels.

\section{INTRODUCTION}

Fresh frozen plasma is frequently given to preterm infants at the neonatal intensive care unit (NICU), but with large regional differences. ${ }^{1-3} \mathrm{Up}$ to $15 \%$ of the infants admitted to NICUs received one or more plasma transfusions when all birth weights and birth gestational ages (GAs) are included, ${ }^{4}$ with higher frequency among the more immature infants. ${ }^{15}$ Indications for the plasma transfusions vary, with the perceived risk of bleeding with

\section{What is already known on this topic?}

- Very preterm infants often receive plasma transfusions within their first weeks of life.

- In most neonatal care settings, donor plasma for transfusion is exclusively derived from male adults

What this study adds?

- The sex steroid profile of male adult donor plasma differs substantially from that of preterm infant plasma.

- Preterm infant circulating sex steroid levels are similar before and after a transfusion with adult male plasma

\section{How this study might affect research, practice or policy?}

More studies are needed to clarify the metabolic fate of the donor plasma steroids in the preterm infant and their possible effect on peripheral tissues.

abnormal coagulation values, arterial hypotension or affected peripheral circulation as common reasons.

Blood products used for transfusion to neonates are derived from adult donors. As there is a risk for immune-mediated transfusion reactions when plasma from female donors with a history of pregnancy is used, ${ }^{67}$ in most care settings, only male donor plasma is considered for transfusion. Plasma is a complex matrix, containing a diversity of bioactive compounds with varying concentrations, depending on age and gender, among other factors. Little is known about the potential impact of factors supplied from adult male donors to the neonate during plasma transfusions.

The fetoplacental unit is untimely broken after preterm birth, thereby interrupting the transfer of sex steroids, steroid precursors and the intricate signalling between mother and fetus. The fetal adrenal cortex is a major site for steroid hormone 
synthesis during pregnancy, regulating intrauterine homeostasis and stimulating organ maturation. ${ }^{8}$ Maturity of the fetal adrenal cortex is related to GA, and preterm infants display a reduced capacity of adrenal steroid synthesis at birth ${ }^{9}{ }^{10}$ coupled to an altered ability for extrauterine adaptation. ${ }^{11} 12$

Considerable fractions of androgens and oestrogens in the blood are bound to sex hormone-binding globulin (SHBG). In the SHBG-bond state, these hormones, including testosterone and oestradiol, are thought to be biologically inactive. Although SHBG levels are significantly lower in fetal serum compared with maternal, the fetal serum concentration of SHBG exceeds that of testosterone, oestradiol and dihydrotestosterone (DHT). ${ }^{13}$ It has been hypothesised that fetal SHBG can protect female fetuses from exposure to androgens and could also play a role in male sex differentiation by modulating the pool of active androgens. ${ }^{14}$

The effect on preterm infant plasma levels of sex steroids following transfusions is unknown. Hypothetically, excess sex steroids from plasma transfusion could alter infant levels and impose an endocrine effect on these susceptible patients. Furthermore, exogenous steroids supplied via transfusions may compete with endogenous steroids produced by the fetal zone for steroid receptor binding. ${ }^{15}$ One case report described a female neonate that developed clitoromegaly during the second month of life after repeated whole blood transfusions from her father. ${ }^{16}$ The infant was found to have high plasma testosterone levels, and the authors suggested that the masculinisation effect was attributed to the transfusions.

This study aimed to investigate if transfusion with male adult plasma affects circulatory sex steroid levels in receiving preterm infants.

\section{METHODS}

\section{Study cohort}

Infants were recruited at the NICU at three centres in Sweden: Queen Silvia Children's Hospital at the Sahlgrenska University Hospital in Gothenburg $(n=10)$, Astrid Lindgren Children's Hospital Huddinge at the Karolinska University Hospital in Stockholm $(n=1)$ and Skåne University Hospital in Lund $(n=8)$. Inclusion criteria were GA at birth $<30$ weeks and a postnatal age of $<10$ days. Exclusion criteria were previous plasma transfusion and severe malformations. Study participants were recruited between November 2015 and November 2016. Donor plasma was administered through a venous catheter during 30-120 min at a dose of $10-15 \mathrm{~mL} / \mathrm{kg}$ according to clinical routines.

\section{Sample collection}

EDTA plasma samples were collected immediately before the start and immediately after the completed transfusion, and then at 6,12, 48 and 72 hours after the transfusion. If an additional transfusion started within 72 hours after the first transfusion, a blood sample was taken 72 hours after the end of the second transfusion. Within 1 hour after collection, samples were centrifuged $10 \mathrm{~min}$ at $1500 \mathrm{~g}$ and the plasma was stored in $0.5 \mathrm{~mL}$ cryotubes at $-80^{\circ} \mathrm{C}$. A portion of plasma $(2 \mathrm{~mL})$ was collected from donor plasma units and stored together with the infant samples. All samples were thawed and refrozen once before analysis. The number of samples analysed for sex steroids and SHBG according to time point and gender is presented in online supplemental table 1 .

\section{SHBG and sex steroid analysis}

Plasma sex steroids were analysed by a validated gas chromatography-tandem mass spectrometry (GC-MS/MS) method with a lower limit of quantification (LLOQ) for oestradiol, oestrone, testosterone, DHT, progesterone, androstenedione and dehydroepiandrosterone (DHEA) of 0.5, 0.5, 8, 2.5, 74, 12 and $400 \mathrm{pg} / \mathrm{mL}$, respectively. Between 20 and $200 \mu \mathrm{L}$ plasma were used for the analysis. Details of the methods used for the steroid analysis have been previously described. ${ }^{17}$

To calculate the total amount of testosterone present in infant blood plasma, infant plasma volume was assumed to be $50 \mathrm{~mL} /$ kg body weight.

SHBG measurements were performed in a subpopulation of infants using the Human SHBG Quantikine ELISA (cat: DSHBG0B, Bio-Techne, UK) according to the manufacturer's instructions. Plasma samples were diluted at 1:75 and assayed as duplicates. Absorbance was measured at $450 \mathrm{~nm}$ with wavelength correction at $620 \mathrm{~nm}$ (Multiscan FC 3.1, Thermo Fisher Scientific). Sample concentrations were determined by comparison to a 7-point calibration curve with 4-parametric curve fit $\left(\mathrm{R}^{2}>0.99\right)$ using SoftMax Pro Software V.4.6 (Molecular Devices). The inter-assay coefficient of variation (CV) was $9.9 \%$ at $86 \mathrm{nmol} / \mathrm{L}$ and the maximum $\mathrm{CV}$ for duplicate samples was $16.7 \%$.

\section{Statistical analyses}

Statistical analyses were performed using IBM SPSS Statistics, V.27 (IBM Corp, Armonk, New York, USA) and all figures were made with R (The R Foundation for Statistical Computing, Vienna, Austria) and the ggplo2 package. Differences between groups were compared using the non-parametric MannWhitney U-test. Differences between time points with related samples were investigated using Wilcoxon signed-rank test. Steroid measurements below the LLOQ were set to LLOQ/2 for statistical analyses. For all tests, $\mathrm{p}$ values $<0.05$ were considered significant.

\section{RESULTS}

\section{Study cohort}

The clinical characteristics of the study cohort are reported in online supplemental table 2. Nineteen infants with a median (min, max) GA at birth of 25.3 (22.9-28.9) weeks were included in the study. All infants received their studied plasma transfusion within 5 days after birth. The median (min, max) volume of plasma transfused was $9.0(6.0-15.0) \mathrm{mL} / \mathrm{kg}$. Within 72 hours after completing the studied transfusion, eight infants received a second plasma transfusion and one infant received a third plasma transfusion.

\section{Sex steroids in donor plasma and infant plasma before start of transfusion}

Before transfusion start, the plasma concentration of three of the analysed sex steroids differed between male and female infants: testosterone, DHT and oestradiol were significantly lower in females than in males (figure 1 and table 1). Therefore, these steroids were analysed separately for males and females.

The median testosterone, DHT and oestradiol concentrations were 116, 21 and 64 times higher in donor plasma compared with female infant plasma, respectively (figure $1 \mathrm{~A}-\mathrm{C}$ ). There were no significant concentration differences between donor plasma and male infant plasma for testosterone and DHT, while the median concentration of oestradiol was 64 times higher in donor plasma than in the infant males.

Among the sex steroids without a gender difference before transfusion start, the concentrations of progesterone (figure 1D), DHEA (figure 1E) and androstenedione (figure 1F) 

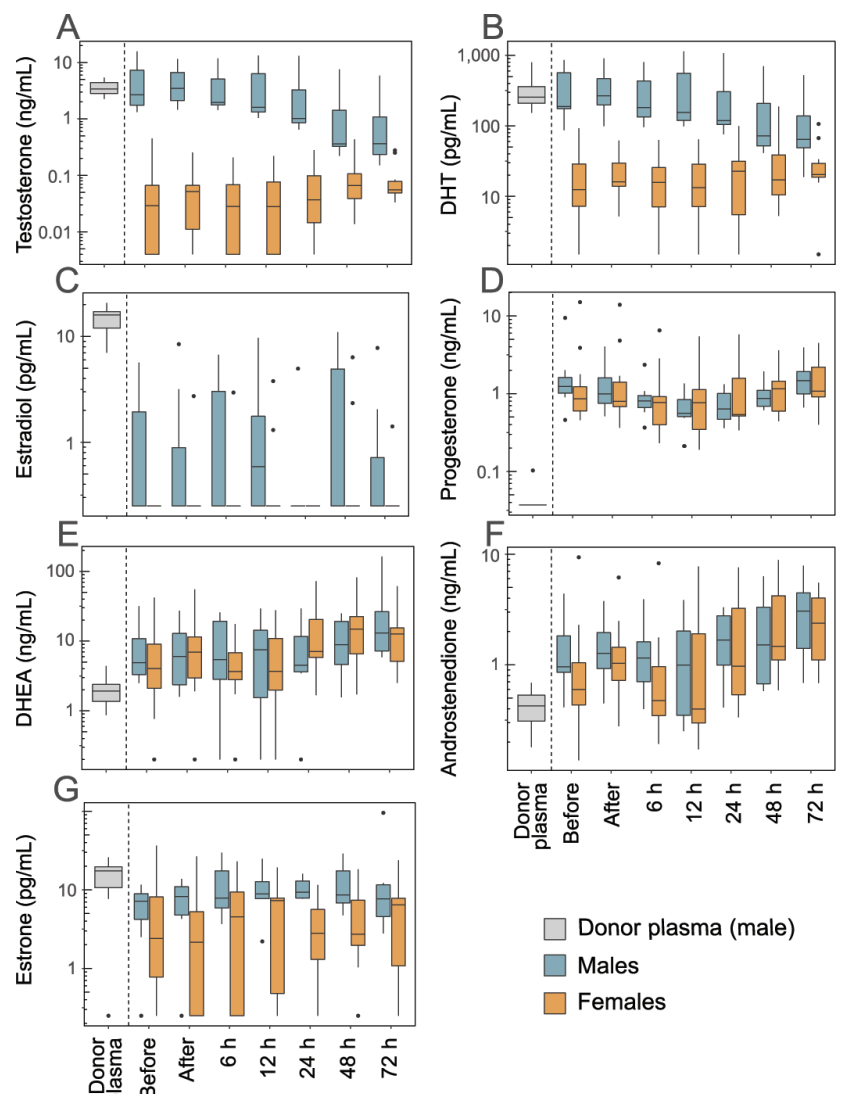

Figure 1 Sex steroids in donor plasma and infant plasma. Sex steroids were analysed in donor plasma and infant plasma just before and after completed plasma transfusion, and then followed 72 hours after the end of the transfusion. (A) Testosterone; (B) dihydrotestosterone (DHT); (C) oestradiol; (D) progesterone; (E) dehydroepiandrosterone (DHEA); (F) androstenedione; $(\mathrm{G})$ oestrone. Boxes show median and IQR, whiskers the largest/smallest value within 1.5 times of the IQR, and outliers are individually plotted. Note that the y-axes are on the logarithmic scale.

were significantly higher in infant plasma compared with donor plasma, while oestrone (figure $1 \mathrm{G}$ ) was lower in infant plasma (table 1).

\section{Sex steroid levels in infant plasma after transfusion}

To investigate the impact of the plasma transfusion on infant sex steroids, we compared steroid levels in infant plasma before and after completed transfusion. No significant changes in any of the analysed sex steroids were observed in relation to the transfusion (table 2). Furthermore, there was no apparent influence of the transfusion on infant plasma sex steroid levels over the 72 hours following the transfusion (figure 1). No further changes in plasma steroids were observed in infants who received a second $(\mathrm{n}=8)$ or third $(\mathrm{n}=1)$ plasma transfusion during the study period (data not shown).

As testosterone was the steroid showing the largest concentration difference between donor plasma and infant female plasma before transfusion, we further studied this hormone. Figure 2 shows the total amount of testosterone given via the transfusion compared with the total approximated amount present in infant plasma before the transfusion. In male infants, the amount of plasma testosterone was up to 20 times higher than that given via the transfusion. In female infants, testosterone provided via the transfusion was up to 600 times higher than that present in endogenous plasma.

\section{Influence of adult plasma on infant SHBG levels}

Levels of SHBG were determined in a subpopulation of the cohort (five males and five females). The plasma SHBG concentration did not differ between genders before transfusion start $(p=0.92$, figure $3 \mathrm{~A}$ ). The SHBG concentration was significantly higher in donor plasma (median (Q1-Q3) 22.8 (17.1-33.5) nmol/L) compared with infant plasma (10.2 (9.1-12.3) nmol/L) before transfusion start $(p=0.01)$. Among the few infants who had both a before and an after transfusion sample $(n=8)$, there was a nonsignificant increase in plasma SHBG following the transfusion (10.2 (8.0-13.3) to $16.2(9.1-19.5) \mathrm{nmol} / \mathrm{L}, \mathrm{p}=0.21)$.

\section{DISCUSSION}

The results show that male adult donor plasma and very preterm infant plasma differ considerably in their sex steroid composition and concentrations. The largest differences were observed between donor and female recipients, particularly among the androgens. Nevertheless, our results indicate that a single plasma transfusion does not impact circulating levels of sex steroids in the recipient preterm infant.

The mean pre-transfusion level of progesterone was within the reference range at postnatal day 1 for infants born at 23-27 weeks' gestation $(2.9 \mathrm{nmol} / \mathrm{L}$ compared with $95 \%$ reference interval $1.9-11.5 \mathrm{nmol} / \mathrm{L}) .^{18}$ Also the pre-transfusion levels of androstenedione and testosterone were within the reference intervals for very preterm infants. ${ }^{19}$ The oestradiol concentration in infant plasma was lower than in donor plasma and in most infant samples also below the LLOQ at $0.5 \mathrm{pg} / \mathrm{mL}$, which

Table 1 Concentrations of sex steroids in infant plasma and donor plasma units before transfusion start

\begin{tabular}{|c|c|c|c|c|c|c|c|c|}
\hline Sex steroid & Donor $(n=19)$ & All infants $(n=19)$ & Boys $(n=7)$ & Girls $(n=12)$ & $\begin{array}{l}P \text {, boys } \\
\text { vs girls }\end{array}$ & $\begin{array}{l}\text { P, donor } \\
\text { vs all }\end{array}$ & $\begin{array}{l}\text { P, donor } \\
\text { vs boys }\end{array}$ & $\begin{array}{l}\text { P, donor vs } \\
\text { girls }\end{array}$ \\
\hline Progesterone $(\mathrm{pg} / \mathrm{mL})$ & $37.0(37.0-37.0)$ & 901 (599-1774) & 1237 (901-1997) & 859 (599-1602) & 0.205 & $<0.001$ & n.t. & n.t. \\
\hline $\begin{array}{l}\text { Dehydroepiandrosterone } \\
(\mathrm{pg} / \mathrm{mL})\end{array}$ & $1918(1325-2408)$ & 4119 (2801-14 625) & 4912 (2801-14 625) & $4031(1308-13031)$ & 0.672 & 0.002 & n.t. & n.t. \\
\hline Androstenedione (pg/mL) & $424(303-534)$ & 842 (443-1684) & 957 (842-1969) & 599 (414-1189) & 0.176 & 0.002 & n.t. & n.t. \\
\hline Testosterone (pg/mL) & $3394(2671-4509)$ & - & 2668 (1650-11 495) & $29.2(4.0-70.7)$ & 0.000 & n.t. & 0.565 & $<0.001$ \\
\hline Dihydrotestosterone $(\mathrm{pg} / \mathrm{mL})$ & $255(208-361)$ & - & $188(171-856)$ & $12.4(6.7-30.5)$ & 0.001 & n.t. & 0.565 & $<0.001$ \\
\hline Oestrone $(\mathrm{pg} / \mathrm{mL})$ & $17.4(10.4-20.1)$ & $3.1(1.1-10.2)$ & $7.2(2.5-10.2)$ & $2.4(0.47-10.8)$ & 0.373 & $<0.001$ & n.t. & n.t. \\
\hline Oestradiol (pg/mL) & $16.0(11.7-17.2)$ & - & $0.25(0.25-2.55)$ & $0.25(0.25-0.25)^{*}$ & 0.021 & n.t. & 0.002 & $<0.001$ \\
\hline
\end{tabular}

Concentrations are reported as medians (Q1-Q3). P, Mann-Whitney U-test.

${ }^{*}$ All measurements below the LLOQ.

LLOQ, lower limit of quantification; n.t., not tested. 
Original research

Table 2 Concentrations of sex steroids in infant plasma directly after completed plasma transfusion

\begin{tabular}{lllllll}
\hline Sex steroid & All infants $(\mathbf{n = 1 8})$ & Boys $(\mathbf{n}=7)$ & Girls $(\mathbf{n}=11)$ & P, all, pre vs post & P, boys, pre vs post & , girls, pre vs post \\
\hline Progesterone $(\mathrm{pg} / \mathrm{mL})$ & $876(700-1703)$ & $990(724-1728)$ & $799(642-1695)$ & 0.349 & n.t. & n.t. \\
Dehydroepiandrosterone $(\mathrm{pg} / \mathrm{mL})$ & $6474(2127-12313)$ & $6015(1746-19698)$ & $6934(2198-11499)$ & 0.943 & n.t. & n.t. \\
Androstenedione $(\mathrm{pg} / \mathrm{mL})$ & $1049(740-1950)$ & $1270(916-1952)$ & $1033(688-1509)$ & 0.215 & n.t. & n.t. \\
Testosterone $(\mathrm{pg} / \mathrm{mL})$ & - & $3471(1742-11456)$ & $52(4.0-70)$ & n.t. & 0.866 & 0.484 \\
Dihydrotestosterone $(\mathrm{pg} / \mathrm{mL})$ & - & $266(157-741)$ & $16.0(12.8-35.6)$ & n.t. & 1.000 & 0.213 \\
Oestrone $(\mathrm{pg} / \mathrm{mL})$ & $4.6(0.25-9.5)$ & $8.2(4.3-12.2)$ & $2.2(0.25-5.6)$ & 0.650 & n.t. & n.t. \\
Oestradiol $(\mathrm{pg} / \mathrm{mL})$ & - & $0.25(0.25-3.2)$ & $0.25(0.25-0.25)$ & n.t. & 0.465 & 0.317 \\
\hline
\end{tabular}

Concentrations are reported as medians (Q1-Q3). P, Wilcoxon signed-rank test.

n.t., not tested.

translates to $1.8 \mathrm{pmol} / \mathrm{L}$. However, Greaves et $a l^{18}$ reported oestradiol 95\% reference interval at day 1 to be $132-523 \mathrm{pmol} / \mathrm{L}$ for infants born at 23-27 weeks' gestation. Also Trotter et al ${ }^{20}$ reported substantially higher plasma oestradiol in extremely preterm female infants in the first week of life than measured in the current study. While we used GC-MS to analyse steroids, Greaves et al and Trotter et al used immunoassays, which likely contributes to the discrepancy in oestradiol concentrations between studies.

The concentrations of testosterone and DHT were unchanged in females after the transfusion although the male donor plasma provided up to 1000 times more of the steroids than present in the infant plasma. Similarly, oestradiol levels were unaffected by the transfusion, although concentrations were on average at least 30 -fold lower in both preterm males and females compared with donor plasma. The lack of an effect of the transfusion on infant plasma steroids has several (mutually non-exclusive) possible explanations: that the provided steroids are rapidly cleared from circulation, metabolised to other products in the infant and/ or instantly accumulated to peripheral tissues, for example, in the adipose tissue, and therefore not detectable in the plasma. Measuring infant urinary steroids and their metabolites may shed further light on the fate of the steroids delivered via plasma transfusions.

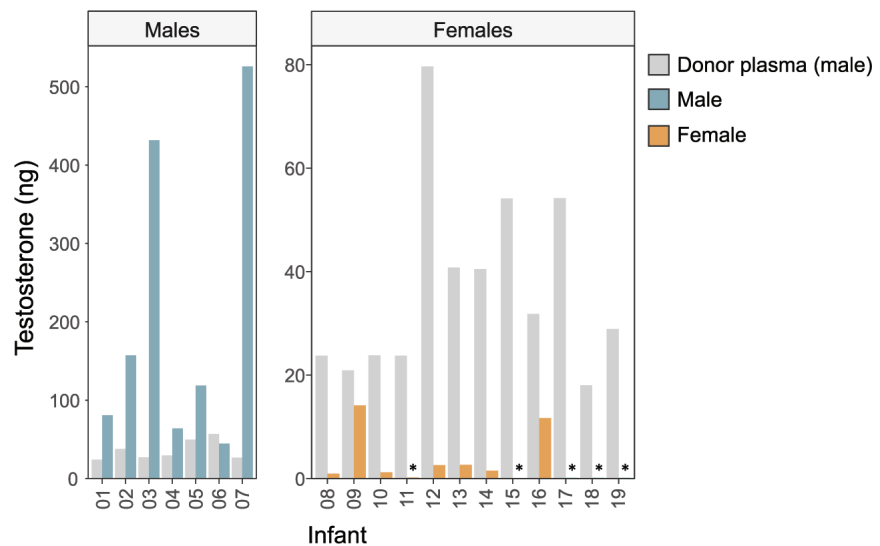

Figure 2 Total testosterone (ng) provided via the plasma transfusion (grey bars) in relation to circulatory amounts in male (blue bars) and female (yellow bars) infants. The total amount of testosterone provided via the plasma transfusion was calculated for each infant and compared with the total amount present in infant plasma before the start of the transfusion (assuming a volume of $50 \mathrm{~mL} / \mathrm{kg}$ plasma in infants). *Plasma concentration below the LLOQ, therefore set to $\mathrm{LLOQ} / 2=4 \mathrm{pg} / \mathrm{mL}$. Note the different $y$-axis scales in males and females. LLOQ, lower limit of quantification.
The transfusion did, on average, deliver $52 \mathrm{ng} / \mathrm{kg}$ testosterone to the infant. When postmenopausal women were treated with a single dose of $100 \mu \mathrm{g}$ inhaled testosterone (corresponding to approximately $1.5 \mu \mathrm{g} / \mathrm{kg}$ ), peak serum levels were observed minutes after the administration and then fell to pre-dose levels over the following $300 \mathrm{~min}^{21}$ In that study, the initial half-life of total testosterone in serum was $10.1 \mathrm{~min}$. Similar results in testosterone pharmacokinetics have been reported after sublingual administration and intravenous infusion of testosterone to women. $^{22}{ }^{23}$ The lack of an increase in plasma testosterone in female infants after plasma transfusion, with a relatively low dose from the donor plasma provided over 1-3 hours, indicates a blood clearance in accordance to that observed in adults. Furthermore, the relatively slow decline of androgens among males suggests that endogenous production remains significant in the first week of life.

Unconjugated steroids, as measured in this study, are hydrophobic molecules that readily diffuse across cellular membranes. ${ }^{24}$ Animal data support tissue uptake of intravenously supplied free steroids and a longer half-life in the tissues compared with blood. $^{25-29}$ For example, Bonsall and Michael $^{29}$ administered $\left[{ }^{3} \mathrm{H}\right]$-testosterone to gonadectomised macaques 1 week after

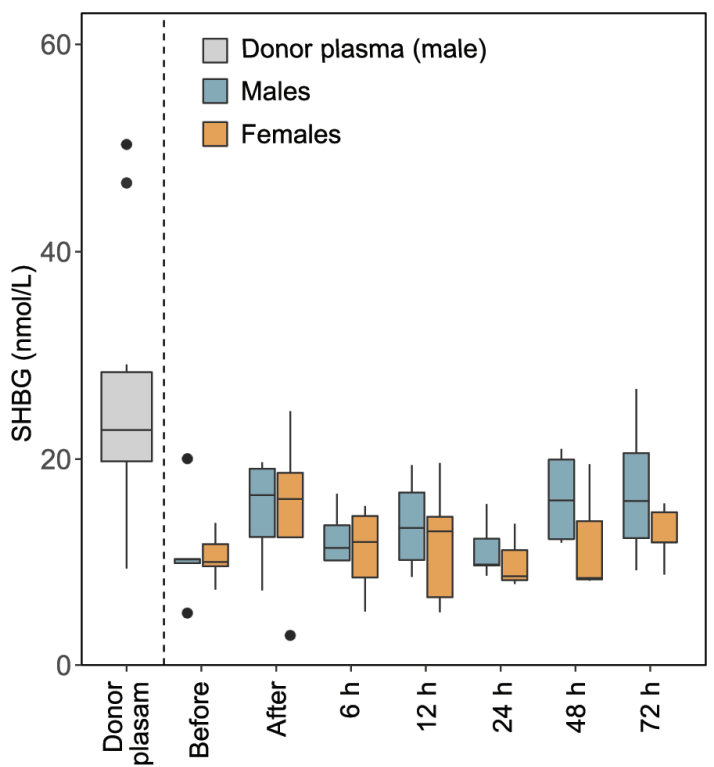

Figure 3 Effect of plasma transfusion on infant plasma levels of sex hormone-binding globulin (SHBG). SHBG was analysed in donor and infant plasma. Infant plasma samples were collected just before and after the completed plasma transfusion, and then followed 72 hours after the end of the transfusion. 
birth and examined sex steroid radioactivity in brain regions and peripheral tissues after $60 \mathrm{~min}$. Both $\left[{ }^{3} \mathrm{H}\right]$-labelled oestradiol and testosterone were detected in different brain regions. In contrast to steroids found in central and peripheral organs, low sex steroid radioactivity was detected in blood $60 \mathrm{~min}$ after administering $\left[{ }^{3} \mathrm{H}\right]$-testosterone. Similar experiments in fetal macaques also support brain uptake of exogenously administered $\left[{ }^{3} \mathrm{H}\right]$-testosterone. ${ }^{28}{ }^{29}$ In neonatal rats, both non-selective and selective uptake of oestradiol into specific brain regions after intravenous administration of $\left[{ }^{3} \mathrm{H}\right]$-oestradiol have been described. ${ }^{30}$ The $\left[{ }^{3} \mathrm{H}\right]$-oestradiol concentration was 3-8 times higher in most brain regions and 80 times higher in the pituitary gland relative to blood after administration. Similarly, plasma infusion with oestrone to fetal sheep significantly enriches the steroid in several fetal brain regions. ${ }^{31}$ Based on these animal studies, it is plausible that excess sex steroids provided via adult plasma transfusions are redistributed and possibly also concentrated into other organs including the brain of the neonate.

Transient virilisation has been reported among girls born very preterm. In some cases, the virilisation has been associated with high androgen levels but with unclear aetiology. ${ }^{32}{ }^{33}$ Repeated male blood transfusions have previously been suggested to be a cause of clitoromegaly. ${ }^{16}$ Our data show that male sex steroids are provided in high quantities with plasma transfusion, but do not provide evidence for a transient increase in serum androgens in association with the transfusion. A possible role for plasma transfusion in female virilisation needs further studies.

Only $1 \%-2 \%$ of the unconjugated steroids in circulation exist in the free active form. The large fraction of plasma steroids is instead bound to SHBG and albumin, and the bioavailability of sex steroids is thought to depend on the concentration of SHBG (the so-called free hormone hypothesis). ${ }^{3435}$ Expression of human SHBG in castrated mice prolongs the half-life of circulatory DHT and testosterone but restricts steroid entry into target tissues. ${ }^{36}$ Thus, a change in plasma SHBG may affect the fraction of bioavailable steroids. SHBG levels in the donor plasma were about two-fold higher than in infants before the transfusion. Although infant plasma SHBG increased by 36\% in response to the transfusion, the change was not statistically significant. Due to the low number of infants included in this analysis, these results must be interpreted with caution and should be investigated in a larger material.

This study has limitations. First, our data indicate that a higher temporal sampling resolution is required to follow the pharmacokinetics of transfusion-supplied steroids. However, additional blood sampling in this fragile patient group may not be ethically justifiable. Second, we only measured circulatory steroid levels and could not follow their distributions to tissues and possible endocrine effects. Third, we determined total plasma steroids, that is, the sum of the free bioavailable and the SHBG-bound fractions. There is evidence that the free fraction of testosterone (and other steroids) is most clinically relevant. ${ }^{37}$ However, determining free steroid levels is difficult, particularly in small volumes such as those available in this study, and most assays suffer from imprecision and inaccuracy. Among the strengths of this study is the simultaneous determination of a panel of sex steroids in donor and infant plasma using a sensitive GC-MS method.

\section{CONCLUSIONS}

We conclude that sex hormones delivered via plasma transfusions from adult male donors do not significantly impact the circulating plasma concentrations in the preterm infant, irrespective of gender. The metabolic fate of the donor plasma steroids in the preterm infant and their possible effect on peripheral tissues and organ systems need further investigation. A first step in elucidating this will be to determine whether sex steroids provided via transfusion are subjected to urinary excretion in the infants.

\section{Author affiliations}

${ }^{1}$ Department of Clinical Neuroscience, Institute of Neuroscience and Physiology, University of Gothenburg Sahlgrenska Academy, Gothenburg, Sweden

${ }^{2}$ Institute of Biomedicine, University of Gothenburg Sahlgrenska Academy, Gothenburg, Sweden

${ }^{3}$ Institute of Health and Care Sciences, University of Gothenburg Sahlgrenska Academy, Gothenburg, Sweden

${ }^{4}$ Department of Internal Medicine and Clinical Nutrition, Institute of Medicine, University of Gothenburg Sahlgrenska Academy, Gothenburg, Sweden

${ }^{5}$ Department of Clinical Chemistry, Sahlgrenska University Hospital, Gothenburg, Sweden

${ }^{6}$ Department of Neonatology, Karolinska University Hospital, Stockholm, Sweden ${ }^{7}$ Department of Clinical Science CLINTEC, Intervention and Technology, Karolinska Institutet, Stockholm, Sweden

${ }^{8}$ Department of Pediatrics, Institute of Clinical Sciences Lund, Lund University Hospital, Lund, Sweden

${ }^{9}$ Institute of Biomedicine, Research Centre for Integrative Physiology and Pharmacology and Turku Center for Disease Modeling, University of Turku, Turku,

Finland

${ }^{10}$ Centre for Bone and Arthritis Research, Sahlgrenska Osteoporosis Centre, Department of Internal Medicine and Clinical Nutrition, Institute of Medicine, University of Gothenburg Sahlgrenska Academy, Gothenburg, Sweden

${ }^{11}$ Department of Drug Treatment, Sahlgrenska University Hospital, Gothenburg, Sweden

Acknowledgements The authors would like to thank all participants and their families. They acknowledge the important work of Margareta Gebka, Ann-Chatrine Berg, Magnus Gram, Mary Gustafsson and Camilla Halzius in sample collection.

Contributors $\mathrm{AKN}, \mathrm{GH}, \mathrm{AL}, \mathrm{CO}$ and $\mathrm{AH}$ developed the concept and design of the study. AL and HR prepared samples and collected mass spectrometry data. All authors contributed to data analysis and interpretation. AKN and GH drafted the manuscript. AH: guarantor for the study.

Funding This work was supported by The Swedish Research Council (DNR\# 2020-01092, 2020-01236), Government grants under the ALF agreement (ALFGBG-717971), The Wallenberg Clinical Scholars, the Torsten Söderberg Foundation, the Novo Nordisk Foundation and Region Skåne Council Foundation for Research and Development.

Competing interests None declared.

Patient consent for publication Consent obtained from parent(s)/guardian(s).

Ethics approval This study involves human participants and was approved by Regional Ethical Board at the University of Gothenburg, Gothenburg, Sweden (Dnr. 315-14 and Dnr. 303-11, T570-15). Participants' parents or legal guardians gave written informed consent to participate in the study before taking part.

Provenance and peer review Not commissioned; externally peer reviewed. Data availability statement Data are available upon request.

Supplemental material This content has been supplied by the author(s). It has not been vetted by BMJ Publishing Group Limited (BMJ) and may not have been peer-reviewed. Any opinions or recommendations discussed are solely those of the author(s) and are not endorsed by BMJ. BMJ disclaims all liability and responsibility arising from any reliance placed on the content. Where the content includes any translated material, BMJ does not warrant the accuracy and reliability of the translations (including but not limited to local regulations, clinical guidelines, terminology, drug names and drug dosages), and is not responsible for any error and/or omissions arising from translation and adaptation or otherwise

Open access This is an open access article distributed in accordance with the Creative Commons Attribution 4.0 Unported (CC BY 4.0) license, which permits others to copy, redistribute, remix, transform and build upon this work for any purpose, provided the original work is properly cited, a link to the licence is given, and indication of whether changes were made. See: https://creativecommons.org/ licenses/by/4.0\%.

\section{ORCID iDs}

Anders K Nilsson http://orcid.org/0000-0003-3631-0783

Dirk Wackernagel http://orcid.org/0000-0001-9887-5160 


\section{REFERENCES}

1 Patel RM, Hendrickson JE, Nellis ME, et al. Variation in neonatal transfusion practice. J Pediatr 2021;235:92-9.

2 Raban MS, Harrison MC. Fresh frozen plasma use in a neonatal unit in South Africa. J Trop Pediatr 2015;61:266-71.

3 Motta M, Del Vecchio A, Perrone B, et al. Fresh frozen plasma use in the NICU: a prospective, observational, multicentred study. Arch Dis Child Fetal Neonatal Ed 2014;99:F303-8.

4 Keir AK, Stanworth SJ. Neonatal plasma transfusion: an evidence-based review. Transfus Med Rev 2016:30:174-82.

5 Keir AK, Yang J, Harrison A, et al. Temporal changes in blood product usage in preterm neonates born at less than 30 weeks' gestation in Canada. Transfusion 2015;55:1340-6.

6 Murphy T, Chawla A, Tucker R, et al. Impact of blood donor sex on Transfusion-Related outcomes in preterm infants. J Pediatr 2018;201:215-20.

7 Middelburg RA, Van Stein D, Zupanska B, et al. Female donors and transfusion-related acute lung injury: a case-referent study from the International TRALI Unisex Research Group. Transfusion 2010;50:2447-54.

8 Ishimoto H, Jaffe RB. Development and function of the human fetal adrenal cortex: a key component in the feto-placental unit. Endocr Rev 2011;32:317-55.

9 Bolt RJ, Van Weissenbruch MM, Popp-Snijders C, et al. Maturity of the adrenal cortex in very preterm infants is related to gestational age. Pediatr Res 2002;52:405-10.

10 Travers S, Martinerie L, Boileau P, et al. Alterations of adrenal steroidomic profiles in preterm infants at birth. Arch Dis Child Fetal Neonatal Ed 2018;103:F143-51.

11 Hanna CE, Keith LD, Colasurdo MA, et al. Hypothalamic pituitary adrenal function in the extremely low birth weight infant. J Clin Endocrinol Metab 1993;76:384-7.

12 Heckmann M, Hartmann MF, Kampschulte B, et al. Cortisol production rates in preterm infants in relation to growth and illness: a noninvasive prospective study using gas chromatography-mass spectrometry. J Clin Endocrinol Metab 2005;90:5737-42.

13 Abramovich DR, Towler CM, Bohn $\mathrm{H}$. The binding of sex steroids in human materna and fetal blood at different stages of gestation. J Steroid Biochem 1978;9:791-4.

14 Hammond GL. Diverse roles for sex hormone-binding globulin in reproduction. Biol Reprod 2011;85:431-41.

15 Hübner S, Sunny DE, Pöhlke C, et al. Protective effects of fetal zone steroids are comparable to estradiol in hyperoxia-induced cell death of immature glia. Endocrinology 2017;158:1419-35.

16 Akçam M, Topaloglu Akemal. Extremely immature infant who developed clitoromegaly during the second month of her postnatal life probably due to frequent whole blood transfusion from an adult male. Pediatr Int 2003;45:347-8.

17 Nilsson ME, Vandenput L, Tivesten Åsa, et al. Measurement of a comprehensive sex steroid profile in rodent serum by high-sensitive gas chromatography-tandem mass spectrometry. Endocrinology 2015;156:2492-502.

18 Greaves RF, Zacharin MR, Donath SM, et al. Establishment of hormone reference intervals for infants born $<30$ weeks' gestation. Clin Biochem 2014;47:101-8.
19 Greaves RF, Pitkin J, Ho CS, et al. Hormone modeling in preterm neonates: establishment of pituitary and steroid hormone reference intervals. J Clin Endocrinol Metab 2015;100:1097-103.

20 Trotter A, Maier L, Grill HJ, et al. Effects of postnatal estradiol and progesterone replacement in extremely preterm infants. J Clin Endocrinol Metab 1999;84:4531-5.

21 Davison S, Thipphawong J, Blanchard J, et al. Pharmacokinetics and acute safety of inhaled testosterone in postmenopausal women. J Clin Pharmacol 2005;45:177-84.

22 Serafini P, Silva PD, Paulson RJ, et al. Acute modulation of the hypothalamicpituitary axis by intravenous testosterone in normal women. Am J Obstet Gynecol 1986;155:1288-92.

23 Tuiten A, Van Honk J, Koppeschaar H, et al. Time course of effects of testosterone administration on sexual arousal in women. Arch Gen Psychiatry 2000;57:149-53. discussion 55-6.

24 Giorgi EP, Stein WD. The transport of steroids into animal cells in culture. Endocrinology 1981;108:688-97.

25 Banks WA, Morley JE, Niehoff ML, et al. Delivery of testosterone to the brain by intranasal administration: comparison to intravenous testosterone. J Drug Target 2009;17:91-7

26 Doherty PC, Sheridan PJ. Uptake and retention of androgen in neurons of the brain of the golden hamster. Brain Res 1981;219:327-34.

27 Bonsall RW, Rees HD, Michael RP. The distribution, nuclear uptake and metabolism of $[3 \mathrm{H}]$ dihydrotestosterone in the brain, pituitary gland and genital tract of the male rhesus monkey. J Steroid Biochem 1985;23:389-98.

28 Michael RP, Bonsall RW, Rees HD. The uptake of [3H]testosterone and its metabolites by the brain and pituitary gland of the fetal macaque. Endocrinology 1989;124:1319-26.

29 Bonsall RW, Michael RP. Developmental changes in the uptake of testosterone by the primate brain. Neuroendocrinology 1992;55:84-91.

30 Eisenfeld AJ, Axelrod J. Selectivity of estrogen distribution in tissues. J Pharmacol Exp Ther 1965;150:469-75

31 Wood CE, Gridley KE, Keller-Wood M. Biological activity of 17beta-estradiol-3-sulfate in ovine fetal plasma and uptake in fetal brain. Endocrinology 2003;144:599-604.

32 Couch R, Girgis R. Postnatal virilization mimicking 21-hydroxylase deficiency in 3 very premature infants. Pediatrics 2012;129:e1364-7.

33 Dumont T, Black AY, Ahmet A, et al. Isolated transient neonatal clitoromegaly with hyperandrogenism of unknown etiology. J Pediatr Adolesc Gynecol 2009;22:e142-5.

34 Mendel CM. The free hormone hypothesis: a physiologically based mathematical model. Endocr Rev 1989;10:232-74.

35 Laurent MR, Helsen C, Antonio L, et al. Effects of sex hormone-binding globulin (SHBG) on androgen bioactivity in vitro. Mol Cell Endocrinol 2016;437:280-91.

36 Laurent MR, Hammond GL, Blokland M, et al. Sex hormone-binding globulin regulation of androgen bioactivity in vivo: validation of the free hormone hypothesis. Sci Rep 2016;6:35539.

37 Goldman AL, Bhasin S, Wu FCW, et al. A reappraisal of testosterone's binding in circulation: physiological and clinical implications. Endocr Rev 2017;38:302-24. 